\title{
Physicochemical Analysis of the Polydimethylsiloxane Interlayer Influence on a Hydroxyapatite Doped with Silver Coating
}

\author{
C. L. Popa, ${ }^{1,2}$ A. Groza, ${ }^{3}$ P. Chapon, ${ }^{4}$ C. S. Ciobanu, ${ }^{1}$ R. V. Ghita, \\ R. Trusca, ${ }^{5}$ M. Ganciu, ${ }^{3}$ and D. Predoi ${ }^{1}$ \\ ${ }^{1}$ National Institute for Materials Physics, P.O. Box MG 07, Magurele, 077125 Bucharest, Romania \\ ${ }^{2}$ Faculty of Physics, University of Bucharest, 405 Atomistilor Street, P.O. Box MG1, 077125 Magurele, Romania \\ ${ }^{3}$ National Institute for Laser, Plasma and Radiation Physics, 409 Atomistilor Street, \\ P.O. Box MG 36, Magurele, 077125 Bucharest, Romania \\ ${ }^{4}$ Horiba Jobin Yvon S.A., 16-18 rue du Canal, 91165 Longjumeau Cedex, France \\ ${ }^{5}$ S.C. METAV R\&D S.A., 020011 Bucharest, Romania \\ Correspondence should be addressed to A. Groza; andreea@infim.ro and D. Predoi; dpredoi@gmail.com
}

Received 6 October 2014; Revised 15 December 2014; Accepted 15 December 2014

Academic Editor: Jen-Jie Chieh

Copyright (C) 2015 C. L. Popa et al. This is an open access article distributed under the Creative Commons Attribution License, which permits unrestricted use, distribution, and reproduction in any medium, provided the original work is properly cited.

We investigate by different complementary methods the processes occurring when a polydimethylsiloxane film is used as interlayer for a silver doped hydroxyapatite coating. The X-ray diffraction and Fourier Transform Infrared Spectroscopy measurements show that the hydroxyapatite doped with silver is in a crystalline form and some $\mathrm{SiO}_{4}{ }^{4-}$ ions formation takes place at the surface and in the bulk of the new hydroxyapatite doped with silver/polydimethylsiloxane composite layer. The possibility of $\mathrm{SiO}_{4}{ }^{4-}$ ions incorporation in the structure of silver doped hydroxyapatite by the mechanism of $\mathrm{SiO}_{4}{ }^{4-} / \mathrm{PO}_{4}{ }^{3-}$ ions substitution is analysed. The new formed silver doped hydroxyapatite/polydimethylsiloxane composite layer is compact, homogeneous, with no cracks as it was shown by Scanning Electron Microscopy and Glow Discharge Optical Emission Spectrometry.

\section{Introduction}

Hydroxyapatite (HAp, $\left.\mathrm{Ca}_{10}\left(\mathrm{PO}_{4}\right)_{6}(\mathrm{OH})_{2}\right)$ is a biomaterial with a wide range of applications in medicine due to its biocompatibility, bioactivity, and osteoconductivity [1-4]. Hydroxyapatite has been used to fill a wide range of bony defects in orthopedic and maxillofacial surgeries and dentistry [5-8]. It has also been widely used as a coating for metallic prostheses to improve their biological properties [911].

From an antibacterial point of view, silver nanoparticles are widely used in medical devices and supplies such as wound dressings, scaffold, skin donation, recipient sites, and sterilized materials in hospitals, medical catheters, contraceptive devices, surgical instruments, bone prostheses, artificial teeth, and bone coating.
Recently, the use of inorganic antibacterial agents, like silver or copper, incorporated in the structure of hydroxyapatite has been shown to be of great interest in the fight against microbes [4]. Hydroxyapatite (HAp) has a very high cation exchange rate with silver ions. Even if at high concentration the silver can be toxic, in small concentrations it has a broad spectrum of antibacterial activity for a wide range of microorganisms like viruses, bacteria, or fungi [2]. Therefore the optimization of the Ag concentration in the HAp structure is critical to guarantee an optimum antibacterial effect without cytotoxicity.

The most common technique to incorporate Ag into HAp structure is via an ion exchange method, in which the $\mathrm{Ca}$ ions in HAp are replaced by Ag ions while dipping the HAp coatings into $\mathrm{AgNO}_{3}$ for a period of time [2]. The limitation of this ion exchange method is that Ag will reside mostly on 
the outer surface of the coating and will be quickly depleted in vivo/in vitro without long-term antibacterial effect.

In our previous studies [11] we presented preliminary results regarding the synthesis, characterization, and antibacterial properties of hydroxyapatite (HAp) and silver doped hydroxyapatite (Ag:HAp). The exact antibacterial action of silver nanoparticles (AgNPs) is not completely understood [12]. On the other hand, in the literature, studies on the preparation and characterization of the silver doped hydroxyapatite powders are almost absent. Antibacterial studies on the Ag:HAp nanopowders are also not presented. Recent studies $[11,13]$ have demonstrated that Ag:HAp nanoparticles prepared by coprecipitation method at $100^{\circ} \mathrm{C}$ show great promise as antibacterial agents against both gram-positive and gram-negative bacteria $[13,14]$.

Coatings of HAp have been deposited as amorphous layers by various techniques like plasma-spray technique, pulsed laser deposition, electrodeposition, sol-gel processing, and radio-frequency magnetron sputtering $[15,16]$. Therefore, the coatings are thermally crystallized at elevated temperatures. During these thermal treatments, many cracks are formed due to a thermal expansion mismatch between the coating and the metal substrate, which severely reduces the bonding strength of the coating layer with the substrate [16].

In order to improve the delamination of HAp coatings different types of interlayers between the substrate and the HAp coating have been used as reinforcement agents. For example, $\mathrm{SiO}_{2}$ layers are known for their own excellent compatibility with the living tissues and their high chemical inertness [17].

The polydimethylsiloxane (PDMS) is an elastomer with biocompatible properties and is frequently used as substrate for biological studies $[6,18]$. The hydrophobic character of a PDMS layer, due to the methyl groups present on its surface, makes it suitable for nonadherent cell culture studies [19]. On the other hand, the oxidation of the PDMS surfaces can be achieved by different treatment methods [19], leading to the formation of hydrophilic $\mathrm{SiO}_{2}$ surfaces which may favor the cells adhesion.

In this paper a method for generation of a Ag:HApPDMS composite layer by thermal evaporation of Ag:HAp nanoparticles and their deposition on the surface of a pure Si disk substrate previously covered with a PDMS layer is presented. The role of the polymer layer and the associated physicochemical processes that take place during the interaction of the hydroxyapatite vapours with the polymer are investigated by Scanning Electron Microscopy (SEM), X-ray diffraction (XRD), Fourier Transform Infrared Spectroscopy (FTIR), and Glow Discharge Optical Emission Spectroscopy (GDOES).

\section{Experimental Section}

2.1. Deposition of PDMS Polymer Layer on Commercially Pure Si Disks. The PDMS layers have been generated in atmospheric air pressure corona discharges starting from liquid precursors of vinyl terminated polydimethylsiloxane. The method and the experimental conditions used for the deposition of thin PDMS layers (with an average thickness in the hundred nanometers range) on metallic substrates were presented in detail in $[8,9]$.

2.2. Silver Doped Hydroxyapatite (Ag:HAp) Nanoparticles. In order to synthesize the silver doped hydroxyapatite (Ag:HAp) precursors of calcium nitrate $\left[\mathrm{Ca}\left(\mathrm{NO}_{3}\right)_{2} \cdot 4 \mathrm{H}_{2} \mathrm{O}\right.$, Aldrich, USA], ammonium hydrogen phosphate $\left(\left(\mathrm{NH}_{4}\right)_{2} \mathrm{HPO}_{4}\right.$; Wako Pure Chemical Industries Ltd.) and $\mathrm{AgNO}_{3}$ (Alpha Aesare, Germany, 99.99\% purity) were used. Controlled amounts of ammonium hydrogen phosphate and silver nitrate were dissolved in ethanol. After adding distilled water, the solution was stirred vigorously for $24 \mathrm{~h}$ at $40^{\circ} \mathrm{C}$. In a separate container, a stoichiometric amount of calcium nitrate was dissolved in ethanol with vigorous stirring for $24 \mathrm{~h}$ at $40^{\circ} \mathrm{C}$. The Ca-containing solution was added slowly to the $\mathrm{P}$-containing solution and then aged at room temperature for $72 \mathrm{~h}$ and further at $40^{\circ} \mathrm{C}$ for $24 \mathrm{~h}$. The composition ratios in the Ag:HAp ( $x_{\mathrm{Ag}}=0$ and $\left.x_{\mathrm{Ag}}=0.5\right)$ sol were adjusted to have $[\mathrm{Ca}+\mathrm{Ag}] / \mathrm{P}$ as 1.67 [11, 47]. The obtained Ag:HAp nanopowders were treated at $800^{\circ} \mathrm{C}$ for 6 hours.

\subsection{Deposition of Ag:HAp Solid Layers on Silicon Substrates} Previously Coated with a PDMS Layer. Starting from an $\mathrm{Ag}: \operatorname{HAp}\left(x_{\mathrm{Ag}}=0.5\right)$ powder (source material), by the thermal evaporation technique, an Ag:HAp solid layer has been deposited on a silicon substrate previously coated with a PDMS film. By this technique the Ag:HAp is evaporated in vacuum. The vapours travel directly to the substrate where they condense to a solid state. A HOCH VACUUM Dresden installation was used under environment conditions. The pressure in the deposition chamber was in the range of $8 \cdot 10^{-5}$ torr. The time range for a deposition cycle was around $120 \mathrm{~min}$. The substrate was maintained at room temperature and at ground electrical potential. The Ag:HAp powder evaporation temperature was $1100^{\circ} \mathrm{C}$. The tungsten boat temperature during the Ag:HAp powder evaporation is in the range of $1178-1205^{\circ} \mathrm{C}$. The distance between substrate and boat is $5 \mathrm{~cm}$.

The evaporation time measured during deposition is situated in the range of $20 \mathrm{sec}$ for a maximum current intensity of $I=75 \mathrm{~A}$ and in the range of $15 \mathrm{sec}$ for a maximum current $I=$ $80 \mathrm{~A}$. Taking into account the deposition characteristics, such as the total amount of HAp totally deposited (in $\mathrm{mg}$ ) and the substrate-boat distance, the calculated evaporation velocities are $v_{1}=0.167 \mathrm{mg} / \mathrm{s}$ or $v_{1} \sim 8.3 \mathrm{~nm} / \mathrm{s}$. The calculated thickness of a $\mathrm{Ag}: \operatorname{HAp}\left(x_{\mathrm{Ag}}=0.5\right)$ layer deposited, in the experimental conditions presented above, on a silicon substrate is about $480 \mathrm{~nm}$. In the presence of a PDMS film, the evaporated Ag:HAp nanoparticles that travel to the substrate condense, being trapped into the polymer bulk. Thus, an Ag:HApPDMS composite layer is generated.

2.4. Samples Characterizations. The morphology of the material was studied using a Quanta Inspect F Scanning Electron Microscope (SEM) equipped within gun beam in emission field, with wolfram filament and with a linear resolution of $5 \mathrm{~nm}$. A part $(10 \mathrm{~mm})$ of a Si substrate with a diameter 
of $20 \mathrm{~mm}$ was covered with a PDMS layer by the method presented above. Then an Ag:HAp layer was deposited by thermal evaporation technique on the entire surface of the Si substrate. The XRD patterns were recorded in the range of $25-55^{\circ}$ using a Philips PW1830 diffractometer with filtered $\mathrm{Cu} \mathrm{K} \alpha$ radiation. The IR spectra of the Ag:HAp-PDMS composite layer formed on a silicon substrate have been obtained using an IR Perkin Elmer spectrometer equipped with a variable angle specular reflectance accessory. In order to perform depth profile studies of the Ag:HAp-PDMS composite layer we varied the angle of incidence light on the sample (equal but opposite to the angle of reflected light) from $30^{\circ}$ to $60^{\circ}$. Here should be: Thus, function of the angle of incidence of the light on the sample the penetration depth of the light into the layer can be changed. For an angle of reflection of $30^{\circ}$, the geometrical position of the variable angle specular reflectance accessory inside the IR spectrometer allows the investigation of the composite layer/substrate interface. As the angle of reflection is increased up to $60^{\circ}$ we can get information about molecules bonds arrangement in the composite layer bulk and as close as possible to the layer surface [9]. For certain spectral ranges, the peak fitting analyses were performed using procedures of Kolmas et al. [48]: (i) baseline correction, (ii) second derivative calculation and self-deconvolution assessment in order to determine the number and positions of the bands, and (iii) curve fittings with fixed peak positions using Lorentzian functions. In the previous studies Matsuhiro and Rivas [49] and Gómez-Ordóñez and Rupérez [50] showed that second derivatives of FTIR spectra are generally used as an aid for wavenumber determination of weak absorption bands or to improve resolution of overlapped bands in the original spectra. To that end, in our studies, derivation including Savitzky-Golay algorithm with nine smoothing points was performed. The depth profile analysis of the Ag:HAp-PDMS composite layer formed on a silicon substrate was performed by Glow Discharge Optical Emission Spectroscopy (GDOES) using a GD Profiler 2 from Horiba/Jobin-Yvon. The selected operating conditions were as follows: $650 \mathrm{~Pa}$ for pressure and $35 \mathrm{~W}$ RF power, working in pulsed mode at $1 \mathrm{kHz}$ pulsing frequency, and a duty cycle of 0.25 . In this technique an area of $4 \mathrm{~mm}$ of the layer is sputtered by a pulsed RF Ar plasma. The sputtered atoms from the layer are then excited by inelastic collisions in the plasma and the emitted lightis monitored in real time providing intensities of the elements of the investigated sample from the surface down to the substrate as a function of time.

An accurate conversion of sputtering time into sputtered depth is not straightforward because the sputtering rate is material dependent and varies during the elemental depth profiling measurement.

\section{Results and Discussions}

3.1. Scanning Electron Microscopy. In Figure 1(a) an image of the interface zone between the Ag:HAp-PDMS composite layer (the dark zone) and the Ag:HAp layer (the light zone) is presented. The polymer acts as a matrix layer for the Ag:HAp coating. Also, it can be observed that both the Ag:HApPDMS composite layer and the Ag:HAp layer are compact and homogeneous with no cracks. In this way, by placing a polymer as interlayer on a material surface intended to be used as substrate for Ag:HAp coating, it is possible to improve its delamination property and thus the adherence of the Ag:HAP layer to the substrate. A high resolution SEM image of the Ag:HAp-PDMS composite layer is presented in Figure 1(b).

3.2. X-Ray Diffraction. XRD patterns of the Ag:HAp nanopowder and the Ag:HAp-PDMS composite layer are shown in Figure 2. All the observed diffraction maxima correspond to the hexagonal hydroxyapatite phase in good agreement with the standard ASTM data (JCPDS number 9-0432). The peaks associated with other phases are not observed. The absence of other phases can indicate an incorporation of $\mathrm{SiO}_{2}$ into the Ag:HAp structure, by substitution of $\mathrm{SiO}_{4}{ }^{4-}$ ions with $\mathrm{PO}_{4}{ }^{3-}$ ions $[51,52]$. The XRD characterizations of the Ag:HAp-PDMS composite layer are endorsed by the surface morphologies observed by SEM (Figure 1).

3.3. Fourier Transform Infrared Spectroscopy (FT-IR). In the following section we will present the FT-IR analysis of each component that constitutes the Ag:HAp-PDMS composite layer.

First, we investigated the polymer structure. The IR spectra and the IR bands assignment of the polymer generated from liquid precursors of vinyl terminated PDMS on a silicon substrate function of the angle of the incident light on the sample are presented in Figure 3 and Table 1.

A possible pathway of the polymerization mechanism of the vinyl terminated PDMS precursors involves the breaking of the double bond of the end group and thus the further linkage of the polymeric chains [9].

As we increase the angle of incident light on the sample up to $60^{\circ}$, it can be observed that the band from $1152 \mathrm{~cm}^{-1}$ increases and the band from $860 \mathrm{~cm}^{-1}$ decreases appearing like a shoulder on the new $880 \mathrm{~cm}^{-1}$ band. The increase of the intensities of the $1152 \mathrm{~cm}^{-1}$ and $880 \mathrm{~cm}^{-1}$ IR bands accompanied by the decrease of $860 \mathrm{~cm}^{-1}$ IR band can be understood knowing that, during the polymerization process of PDMS in negative corona discharge, the formation of the new $\mathrm{Si}-\mathrm{O}$ bonds due to the injection of the negative ions in the liquid precursor bulk is associated with the diminishing of $\mathrm{Si}-\mathrm{CH}_{3}$ bonds $[9,53]$. Thus, in the polymer layer bulk, mainly at the polymer layer surface $\mathrm{SiO}_{2}$ structures [9] can be generated.

In the same time, in [9] it was mentioned that during the polymerization process of PDMS in negative corona discharge in air at atmospheric pressure some water molecules can be injected into the layer bulk. They can be decomposed in $\mathrm{OH}$ groups due to the high electric fields associated with corona discharges $[9,54]$.

Therefore, the band from $1650 \mathrm{~cm}^{-1}$ present in the IR spectrum of the PDMS polymer, assigned to partly hydrated silica and to the stretching vibrations of adsorbed $\mathrm{OH}$ group 


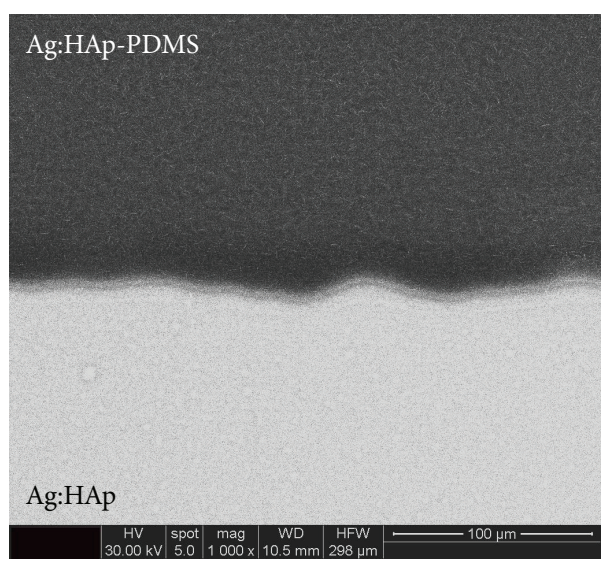

(a)

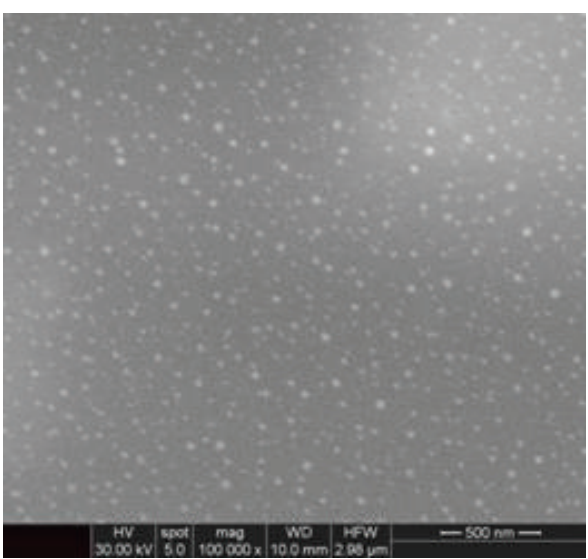

(b)

FIGURE 1: SEM image of (a) interface between the Ag:HAp-PDMS composite layer and the Ag:HAp layer and (b) Ag:HAp-PDMS composite layer.

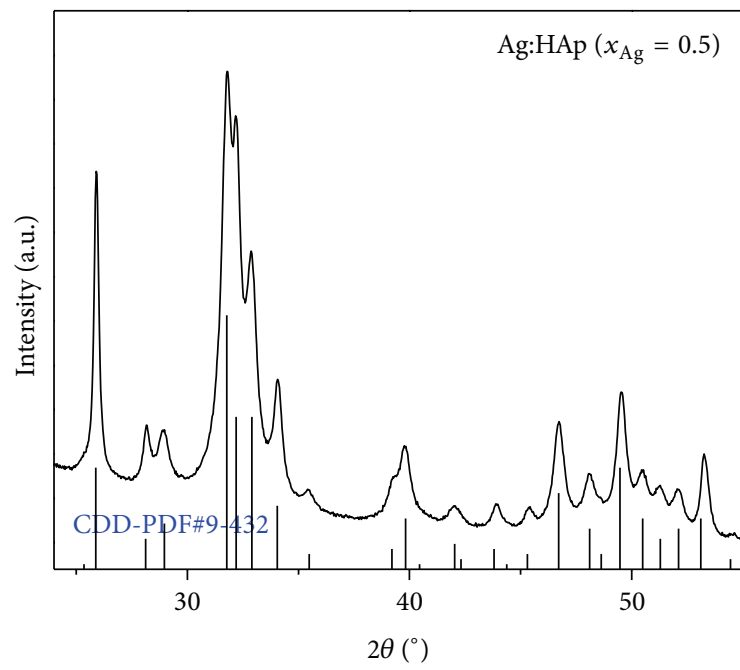

(a)

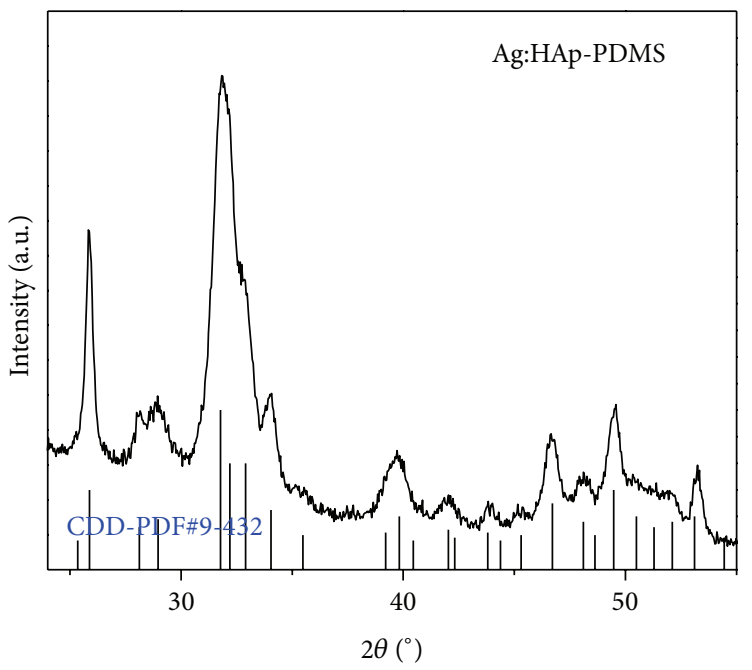

(b)

FIGURE 2: XRD diffraction patterns of the Ag:HAp nanopowder (a) and the Ag:HAp-PDMS composite layer (b).

respectively $(\mathrm{Si}-\mathrm{OH})[46]$ indicates the formation of $\mathrm{Si}-\mathrm{OH}$ group [55]. The existence of the $\mathrm{Si}-\mathrm{OH}$ in the PDMS layer is also suggested by the formation of the new $\mathrm{Si}-\mathrm{O}$ bonds by the possible hydroxylation $\mathrm{Si}-\mathrm{OH}+\mathrm{Si}-\mathrm{OH}=\mathrm{Si}-\mathrm{O}-\mathrm{Si}+\mathrm{H}_{2} \mathrm{O}$ reaction [55].

Second, we performed FT-IR analysis on the Ag:HApPDMS composite layer. The IR spectra are presented in Figure 4. Furthermore, the IR bands assignment is highlighted in Table 1.

The IR band from $1152 \mathrm{~cm}^{-1}$, Figure 3, is shifted to $1140 \mathrm{~cm}^{-1}$, Figure 4, being visible only in the spectrum obtained for an angle of incident light on the sample of $60^{\circ}$. The shift of this band and its absence in the IR spectra obtained at $r=30^{\circ}, 40^{\circ}$, and $50^{\circ}$, respectively, Figure 4 , can indicate the rearrangements of $\mathrm{Si}$ and $\mathrm{O}$ atoms in the $\mathrm{SiO}_{2}$ structures when an Ag:HAp layer is deposed, by the thermal evaporation technique, on a substrate previously coated with a PDMS film.

The formation of $\mathrm{SiO}_{4}{ }^{4-}$ groups was evidenced by the 490 and $695 \mathrm{~cm}^{-1}$ IR bands (Figure 4 and Table 1 ).

The 1004 and $1071 \mathrm{~cm}^{-1}$ IR bands (Figure 3 and Table 1) seem to be shifted to 995 and $1066 \mathrm{~cm}^{-1}$ (Figure 4), respectively, possibly due to the overlapping of IR bands characteristics to PDMS and Ag:HAp.

In comparison with the IR spectrum of the PDMS layer (Figure 3), in the IR spectrum of Ag:HAp-PDMS composite layer (Figure 4) we can observe a broad band in 3000$3600 \mathrm{~cm}^{-1}$ region due to the adsorbed $\mathrm{H}_{2} \mathrm{O}$ from the Ag:HAp structure, $\mathrm{OH}$ or $\mathrm{Si}-\mathrm{OH}$ groups $[36,46]$, its intensity being diminished as we approach the surface of the Ag:HAp-PDMS composite layer (Figure 4). The diminishing of the band intensity as close as possible to the surface layer can be 
TABLE 1: FT-IR bands associated with the functional groups present in the structure of Ag:HAp-PDMS composite layer.

\begin{tabular}{|c|c|c|}
\hline \multirow{2}{*}{ Wavenumber $\left(\mathrm{cm}^{-1}\right)$} & \multicolumn{2}{|c|}{ IR bands assignment } \\
\hline & PDMS layer & Ag:HAP-PDMS layer \\
\hline 490 & - & $\mathrm{SiO}_{4}^{4-}[20-23]$, Figure 4 \\
\hline $498,512,543,550$ & - & $\mathrm{SiO}_{4}^{4-}[24,25]$, Figure 5(a) \\
\hline $562,590,602,611$ & - & $\begin{array}{c}\mathrm{P}-\mathrm{O} \text { bending vibrations in } \mathrm{PO}_{4}{ }^{3-} \\
\text { tetrahedron in crystalline HAP } \\
{[20-23,26-35] \text {, Figure 5(a) }}\end{array}$ \\
\hline 620 & $\begin{array}{l}\mathrm{Si}\left(\mathrm{CH}_{3}\right)_{2} \text { asymmetrical stretching } \\
\text { vibration [36], Figure } 3\end{array}$ & - \\
\hline 695 & - & $\begin{array}{c}\text { Crystallinity of } \mathrm{SiO}_{2} \text { type materials [37], } \\
\text { Figure } 4\end{array}$ \\
\hline 780 & - & Si-O-P vibration [38], Figure 5(c) \\
\hline 784 & Si-C stretching vibration [36], Figure 3 & - \\
\hline $814,816,817.5$ & - & Si-O-Si bonds [27, 28], Figure 5(c) \\
\hline 828 & - & Si-O-Ag $[39,40]$, Figure 5(d) \\
\hline 860 & $\mathrm{Si}-\mathrm{CH}_{3}$ rocking vibration [36], Figure 3 & - \\
\hline 862 & - & Si-O, Si-C vibrations [28], Figure 5(e) \\
\hline 870 & - & $\mathrm{CO}_{3}{ }^{2-}$ vibrations $[20,30,41]$, Figure 5(e) \\
\hline 877 & - & $\mathrm{HPO}_{4}{ }^{2-}$ ions $[32,34,42,43]$, Figure 5(e) \\
\hline 889 & Si-O bending vibration $[37,44]$, Figure 3 & - \\
\hline $925,945,975$ & - & $\begin{array}{l}\mathrm{P}-\mathrm{O} \text { vibrations in } \mathrm{PO}_{4}{ }^{3-} \text { group } \\
{[20-23,26-30,45], \text { Figure } 5(\mathrm{~b})}\end{array}$ \\
\hline 1004,1071 & Si-O-Si vibrations [36], Figure 3 & - \\
\hline $1000,1044,1067,1085$ & - & $\mathrm{PO}_{4}{ }^{3-}[20-23,26-35]$, Figure 5(b) \\
\hline 1140 & - & Si-O vibrations $[9,37,44]$, Figure 4 \\
\hline 1152 & Si-O vibrations $[9,37,44]$, Figure 3 & - \\
\hline 1254,1400 & $\begin{array}{c}\mathrm{CH}_{3} \text { vibrations in } \mathrm{Si}=\mathrm{CH}_{3} \text { group [36], } \\
\text { Figure } 3\end{array}$ & $\begin{array}{c}\mathrm{CH}_{3} \text { vibrations in } \mathrm{Si}=\mathrm{CH}_{3} \text { group [36], } \\
\text { Figure } 4\end{array}$ \\
\hline 1650 & $\mathrm{H}_{2} \mathrm{O}, \mathrm{OH}, \mathrm{Si}-\mathrm{OH}[46]$, Figure 3 & $\mathrm{H}_{2} \mathrm{O}, \mathrm{OH}, \mathrm{Si}-\mathrm{OH}[46]$, Figure 4 \\
\hline 2912,2964 & $\mathrm{C}-\mathrm{H}$ vibrations [36], Figure 3 & - \\
\hline
\end{tabular}

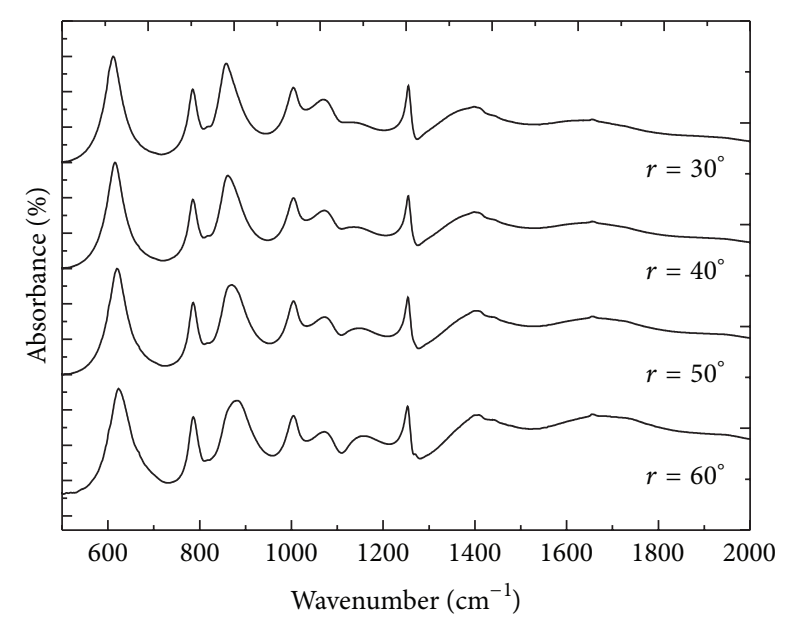

FIGURE 3: IR spectra of a polymer generated from a vinyl terminated polydimethylsiloxane liquid precursors on a silicon substrate for different reflection angles.

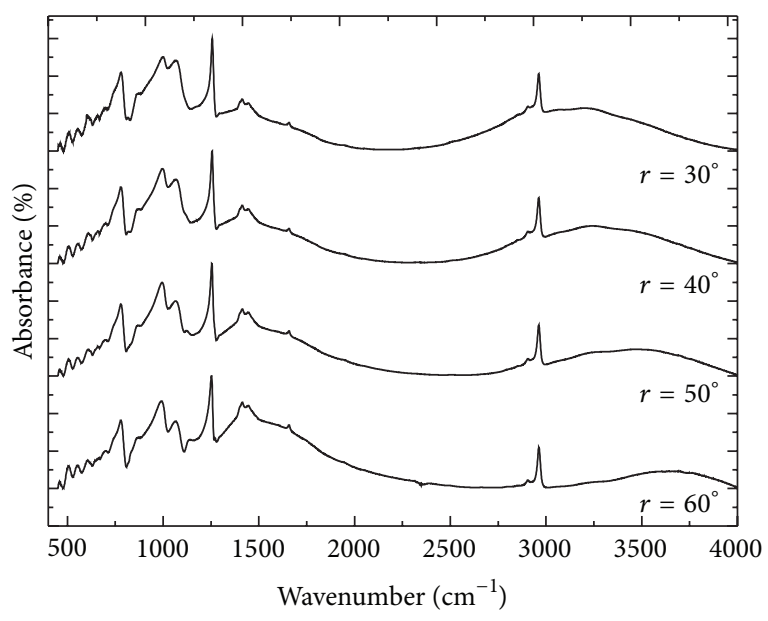

FIGURE 4: FTIR spectra of the Ag:HAp-PDMS composite layer function of the angle of the incident light on the sample. 
explained if we consider that during the deposition process the Ag:HAp evaporated molecules that travel to the substrate diffuse into the PDMS layer bulk, heating it. During the condensation of the Ag:HAp molecules on the substrate, we suppose that several processes, such as the water evaporation and the generation of some new bonds in the bulk of the Ag:HAp-PDMS composite layer, are taking place.

The IR band from $1650 \mathrm{~cm}^{-1}$ observed in the spectrum of the PDMS layer (Figure 3 ) is still present in the spectrum of the Ag:HAp-PDMS composite layer (Figure 4). In some previous studies on polydimethylsiloxane/HAp composites [38], it was shown that an IRband at around $1650 \mathrm{~cm}^{-1}$ originates from the deformational vibrations of hydroxyapatite $\mathrm{OH}$ groups, which form hydrogen bonds with the siliconate $\mathrm{OH}$ groups.

According to previous studies [27, 56], the IR spectral regions specific to chemical bonds present in Si based compounds (mainly $\mathrm{Si}-\mathrm{O}$ ) and HAp (P-O bonds), respectively, are almost similar. Thus, we have performed a peak fitting analysis of the IR spectrum of the Ag:HAp-PDMS composite layer for a proper identification of the processes that take place during its formation (Figure 5). It was previously shown $[24,25,38,57,58]$ that the overlapping of Si-O and P-O bands could indicate the incorporation of $\mathrm{Si}$ based structures in the Ag:HAp.

In Figures 5(a) and 5(b) all the IR bands specific to P$\mathrm{O}$ vibrations in $\mathrm{PO}_{4}{ }^{3-}$ ions and those specific to $\mathrm{Si}-\mathrm{O}$ bonds in $\mathrm{SiO}_{4}{ }^{4-}$ ions which are also summarized in Table 1 can be observed. The appearance of these $\mathrm{Si}-\mathrm{O}$ peaks might indicate a partial loss of phosphate groups and/or of the symmetry at the site caused by substitution of silicate species in $\mathrm{Si}$ HAp $[24,25]$. At the same time, the IR band from $1000 \mathrm{~cm}^{-1}$ (Figure 5(b)) and $925 \mathrm{~cm}^{-1}$ highlights the incorporation of $\mathrm{Si}$ into the HAp structure [57, 58]. Jovanovic et al. [38] suggested that the overlap of the $\mathrm{Si}-\mathrm{O}$ and $\mathrm{P}-\mathrm{O}$ bands might indicate a substitution of $\mathrm{PO}_{4}{ }^{3}$ with $\mathrm{SiO}_{4}{ }^{4-}$.

The results of the peak fitting analysis presented in Figure 5(c) reveal the presence of $\mathrm{Si}-\mathrm{O}-\mathrm{Si}$ bonds specific to inorganic silica moiety [29], also asserting their presence in the Ag:HAp-PDMS composite layer. The $\mathrm{Si}-\mathrm{OH}$ groups are present in the Ag:HAp-PDMS composite layer (Figure 4) due to the formation of the interlinked bonds of Si-O-Ag or Si-O-P type, Figure 5(d). According to [39, 40] a double displacement reaction, $\mathrm{Si}-\mathrm{O}-\mathrm{H}+\mathrm{Ag}^{+}=\mathrm{Si}-\mathrm{O}-\mathrm{Ag}+\mathrm{H}^{+}$, would be expected to have occurred, causing the appearance of Si-O$\mathrm{Ag}$ vibration bands in the FT-IR spectrum of Ag:HAP-PDMS composite layer. Likewise, the $\mathrm{Si}-\mathrm{O}-\mathrm{P}$ bonds can be formed due to the interaction of the siliconate molecules with $\mathrm{OH}$ groups from the structure of hydroxyapatite [38].

In Figure 5(e) the results of the peak fitting analysis obtained in the $850-890 \mathrm{~cm}^{-1}$ spectral region where the overlapping of the $\mathrm{Si}-\mathrm{O}, \mathrm{Si}-\mathrm{C}, \mathrm{HPO}_{4}{ }^{2-}$, and $\mathrm{CO}_{3}{ }^{2-}$ characteristic bands has previously been explained $[20,25,30,32,34,35,41-$ 43] are presented.

The peaks associated with all the functional groups present in the IR spectra of Ag:Hap-PDMS composite layer are summarized in Table 1.
3.4. Glow Discharge Optical Emission Spectrometry (GDOES). In Figure 6(a) the depth profile curves of the Si, O, C, and $\mathrm{H}$ atoms in the bulk and at the surface of the PDMS layer are presented.

The depth profiles of the $\mathrm{P}, \mathrm{Ca}, \mathrm{Ag}$, and $\mathrm{O}$ atoms in a Ag:HAp layer were presented elsewhere [20].

In Figure 6(b) it can be observed that the depth profile curves of all the elements identified in the bulk of the Ag:HAp-PDMS composite layer have similar behaviour. There is no sharp delimitation between the $\mathrm{Ca}, \mathrm{Ag}, \mathrm{P}, \mathrm{O}$, and $\mathrm{H}$ depth profile curves specific to a Ag:HAp layer and those of $\mathrm{Si}, \mathrm{O}, \mathrm{C}$, and $\mathrm{H}$ atoms present in the PDMS layer. This could result from different causes: roughness of the interface (as the GD averages the signals over the entire erosion zone), flatness of the crater bottom, or formation of a composite material. The operating conditions selected for the present analysis provide a flat crater bottom, while for other similar samples [20] the interface did not indicate any roughness. Therefore, the GD results correlate the observations made and tend to indicate that during the deposition process there are some interactions between the Ag:HAp particles and the polymer and thus the formation of a composite material.

Compared to Figure 6(a), in Figure 6(b), the intensity of the $\mathrm{Si}$ depth profile decreases and a broadening of its shape can be also observed. The redistribution of $\mathrm{Si}$ atoms in the bulk of the new composite layer emphasizes the possibility of $\mathrm{Si}$ involvement in the formation of new $\mathrm{Si}-\mathrm{O}, \mathrm{Si}-\mathrm{O}-\mathrm{Ag}$, and $\mathrm{Si}-\mathrm{O}-\mathrm{P}$ chemical bonds. The $\mathrm{Si}$ depth profile curves reach a plateau only after the Ca profile curve drops down.

This observation is an indication of silicon atoms involvement not only in the silicon oxide structures, $\mathrm{Si}-\mathrm{O}-\mathrm{Ag}$ or $\mathrm{Si}-\mathrm{O}-\mathrm{P}$ bonds formation, but also in the structure of the Ag:HAp-PDMS composite layer, in accordance with FT-IR investigations. A plateau in a profile curve followed by an increase is an indication of substrate interface. This kind of behaviour of a certain depth profile curve when all the other depth profile curves decrease is generally observed when an element contained in the investigated layer is also present in the substrate material $[9,59]$.

In the current study we have presented for the first time the formation of an Ag:HAp-PDMS composite layer by deposition of Ag:HAp nanoparticles on a substrate previously coated with a PDMS layer via a simple and reproducible method. The studies of the Ag:HAp-PDMS composite layer are captivating, mainly because of their interesting physicochemical properties and unique structure, which make them attractive for many applications. Due to the presence of Ag in the layer structure, this compound presents a great interest in future biological and biochemical studies. In previous studies [20], it was shown that Ag:HAp thin films have antimicrobial properties against Escherichia coli and Staphylococcus aureus bacteria. According to Shevchenko et al. [40], formation of Si$\mathrm{O}-\mathrm{M}$ linkages can be indicated by the shift of Si asymmetric valence band to the field of lower frequencies. On the other hand, the GDOES analysis showed that during the deposition process there are some interactions between Ag:HAp and the polymer thus forming a new composite material. These results are supported by the presence of vibrational bands associated with $\mathrm{Si}-\mathrm{O}-\mathrm{Ag}$ bonds in the obtained IR spectrum 


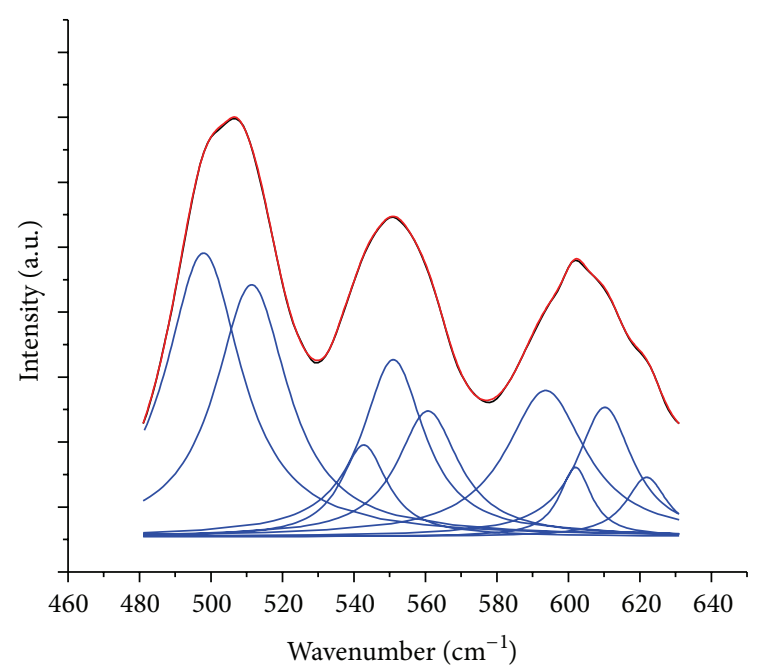

(a)

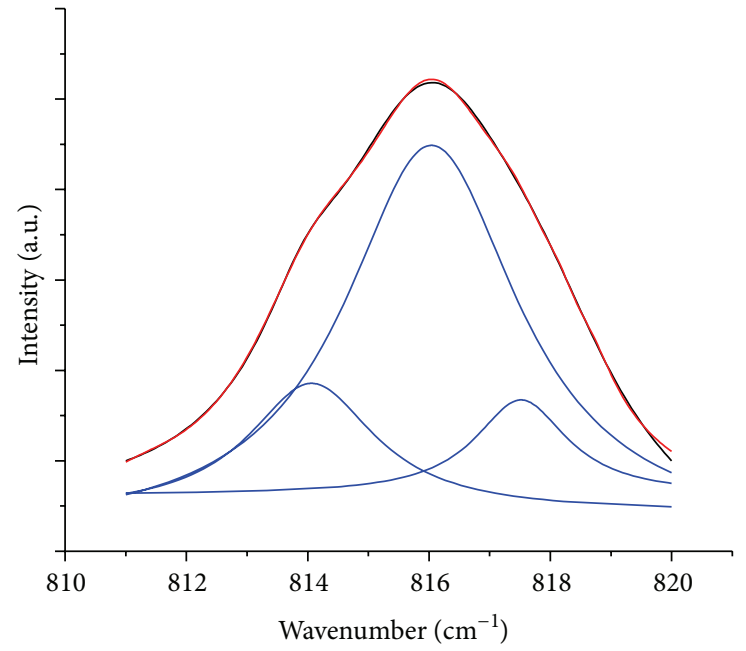

(c)

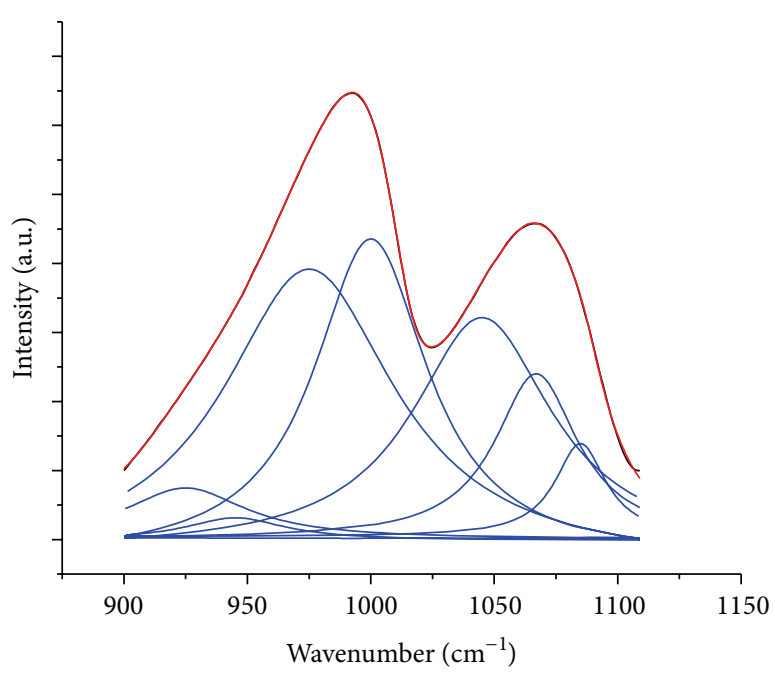

(b)

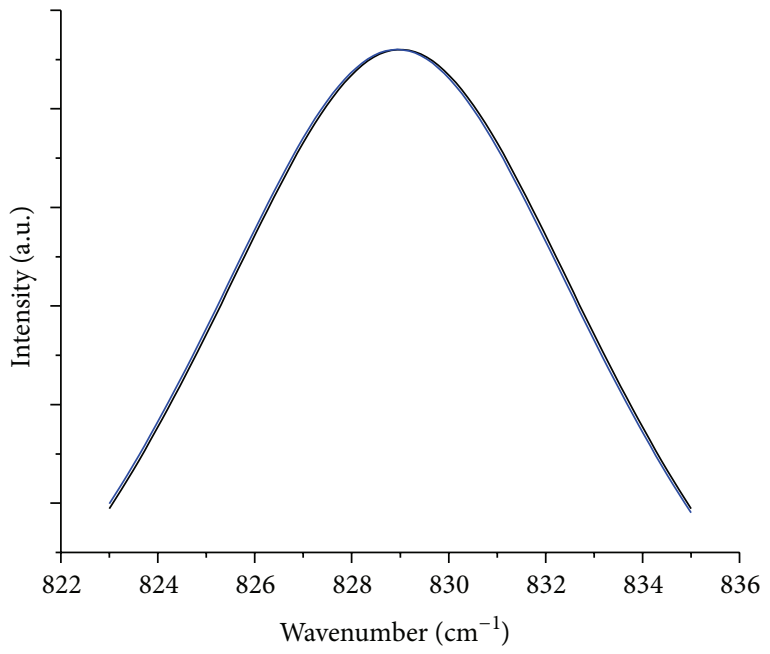

(d)

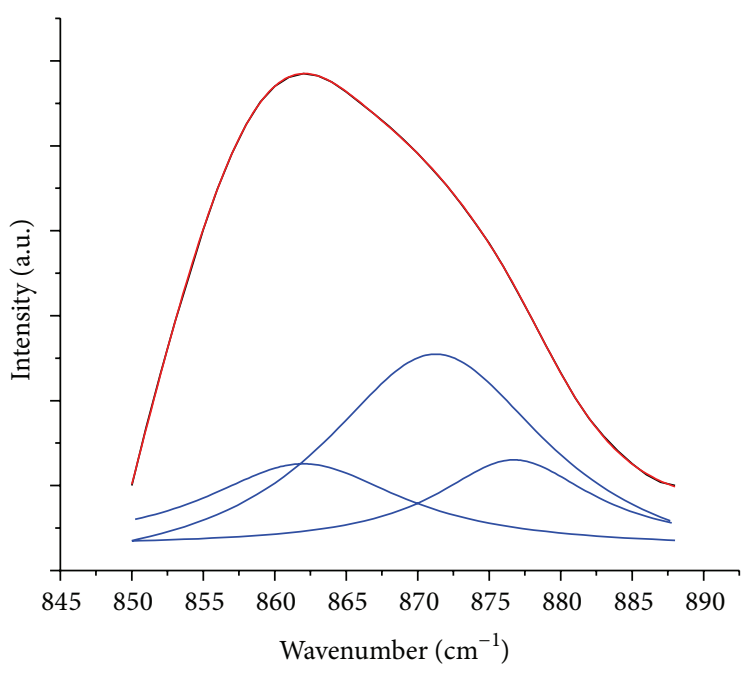

(e)

FIGURE 5: FT-IR deconvoluted spectra of the Ag:HAp-PDMS composite layer in the spectral regions: (a) $450-650 \mathrm{~cm}^{-1},(\mathrm{~b}) 900-1200 \mathrm{~cm}^{-1}$, (c) $810-820 \mathrm{~cm}^{-1}$, (d) $822-835 \mathrm{~cm}^{-1}$, and (e) $850-890 \mathrm{~cm}^{-1}$, for an incident angle of the light on the sample of $60^{\circ}$. The experimental curve is plotted in red and calculated theoretical bands are in blue. 


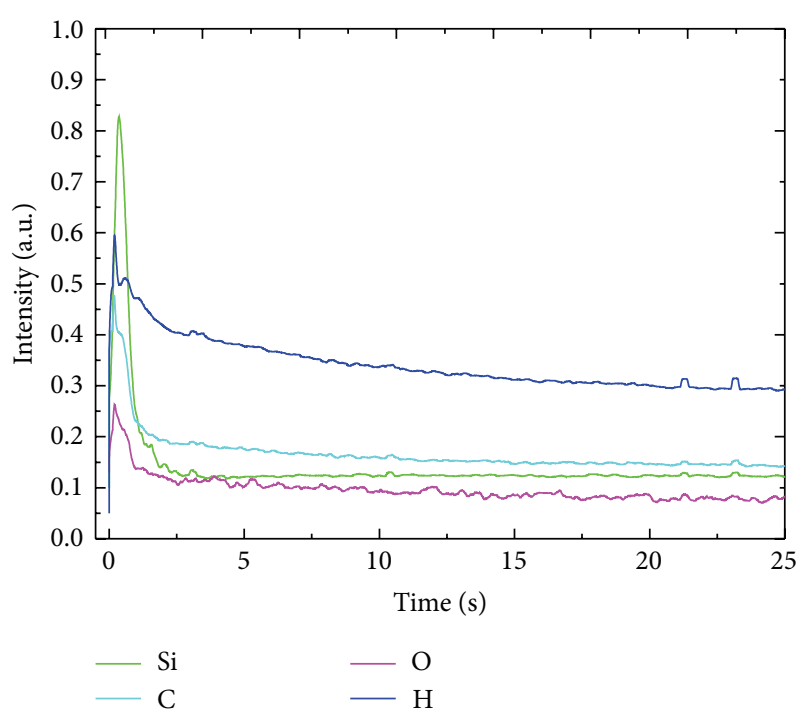

(a)

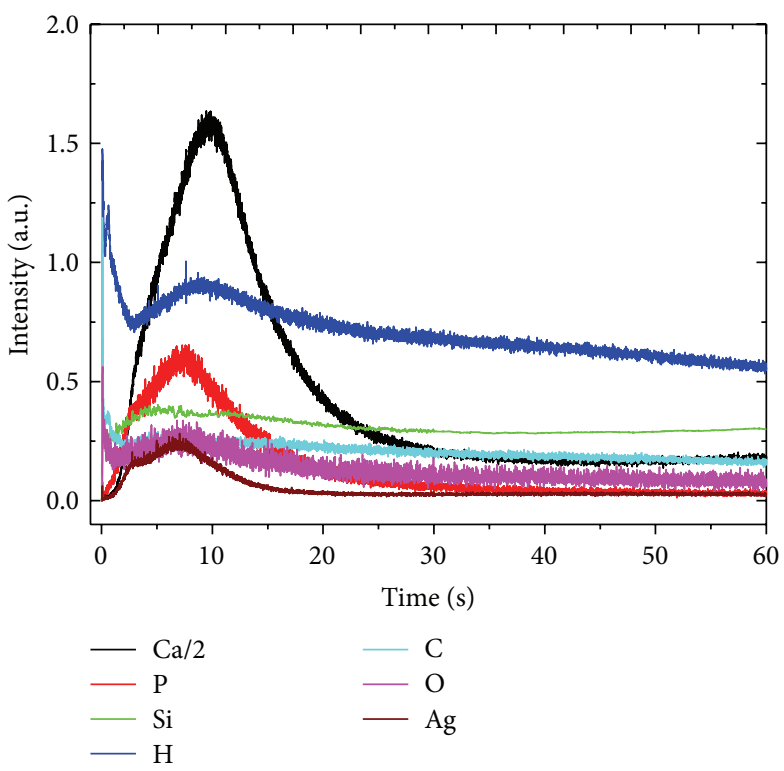

(b)

FIGURE 6: GDOES spectra of (a) PDMS layer and (b) Ag:HAp-PDMS composite layer, generated on a Si substrate.

(Figure 5(d)) which ascertain the presence of Ag in the structure of the Ag:HAp-PDMS composite layer [40]. Moreover, this study develops a novel and facile method to produce composites based on Ag (Ag:HAp-PDMS composite layer) which can be used for large-scale applications.

\section{Conclusions}

In this paper a method for the deposition of a Ag:HAp coating on a substrate previously covered with a PDMS layer is presented. As the SEM investigations showed, the PDMS layer acts as a matrix in which the Ag:Hap is incorporated. In this way, a Ag:HAp-PDMS composite layer is formed. The XRD measurements showed that the crystalline form of the Ag-HAP is maintained in the composite layer.

By FT-IR and GDOES spectral techniques we investigated the physicochemical processes that take place during the interaction of Ag:HAp with the PDMS layer. The FT-IR analysis, in agreement with the XRD measurements, showed that the physical procedure used for the generation of the Ag:HAp-PDMS composite layer is useful for the formation of $\mathrm{SiO}_{4}{ }^{4-}$ ions. On the other hand, the $\mathrm{SiO}_{4}{ }^{4-}$, ions can be incorporated into the Ag:HAp structures substituting the $\mathrm{PO}_{4}{ }^{3-}$ ions from the structure of Ag:HAp. We suppose that after the condensation of the Ag:HAp on the substrate, due to the heating of the $\mathrm{SiO}_{2}$ network present in the polymer bulk, the $\mathrm{SiO}_{4}{ }^{4-}$ ions are generated.

The GDOES depth profiling curves of the Ag:HAp-PDMS composite layer indicate that its composition is homogeneous which can be explained by the formation of the $\mathrm{Si}-\mathrm{O}-\mathrm{Ag}$ and $\mathrm{Si}-\mathrm{O}-\mathrm{P}$ bonds, respectively, and the Si involvement in Ag:HAp structure.

\section{Conflict of Interests}

The authors declare that there is no conflict of interests regarding the publication of this paper. The authors also declare that they do not have any other conflicts to declare.

\section{Acknowledgments}

The financial and encouragement support provided by the Ministry of Education of Romania, Project nos. PN-II-IDPCE-2011-3-0958 and PT-PCCA-2011-3.1-1136, is acknowledged.

\section{References}

[1] A. Dudek and L. Adamczyk, "Properties of hydroxyapatite layers used for implant coatings," Optica Applicata, vol. 43, pp. 143-151, 2013.

[2] C. S. Ciobanu, E. Andronescu, and D. Predoi, "BET and XRD studies on the hydroxyapatite and europium doped hydroxyapatite," Journal of Optoelectronics and Advanced Materials, vol. 13, no. 7, pp. 821-824, 2011.

[3] D.-H. Kim, Y.-M. Kong, S.-H. Lee et al., "Composition and crystallization of hydroxyapatite coating layer formed by electron beam deposition," Journal of the American Ceramic Society, vol. 86, no. 1, pp. 186-188, 2003.

[4] K. Mediaswanti, C. Wen, E. P. Ivanova, C. C. Berndt, and J. Wang, Titanium alloys-Advances in Properties Control, Edited by J. Sieniawski and W. Ziaja, InTech, 2013.

[5] J. C. Selby and M. A. Shannon, "A method to fabricate mesoscopic freestanding polydimethylsiloxane membranes used to probe the rheology of an epithelial sheet," Journal of Biochemical and Biophysical Methods, vol. 70, p. 932, 2008. 
[6] D. Fuard, T. Tzvetkova-Chevolleau, S. Decossas, P. Tracqui, and P. Schiavone, "Optimization of poly-di-methyl-siloxane (PDMS) substrates for studying cellular adhesion and motility," Microelectronic Engineering, vol. 85, no. 5-6, pp. 1289-1293, 2008.

[7] M. Calasans-Maia, E. Sales, J. M. Granjeiro, R. T. Lopes, and I. Lima, "Bone implant interface investigation by synchrotron radiation X-ray microfluorescence," in Proceedings of the 20th International Congress: X-ray Optics and Microanalysis, vol. 1221 of AIP Conference Proceedings, pp. 160-163, Karlsruhe, Germany, 2009.

[8] A. Groza, A. Surmeian, M. Ganciu, and I. I. Popescu, "Infrared spectral investigation of the linseed oil polymerization in a corona discharge in air at atmospheric pressure," Europhysics Letters, vol. 68, no. 5, pp. 652-657, 2004.

[9] A. Groza, A. Surmeian, C. Diplasu et al., "Physico-chemical processes occurring during polymerization of liquid polydimethylsiloxane films on metal substrates under atmospheric pressure air corona discharges," Surface and Coatings Technology, vol. 212, pp. 145-151, 2012.

[10] C. S. Ciobanu, S. L. Iconaru, I. Pasuk et al., "Structural properties of silver doped hydroxyapatite and their biocompatibility," Materials Science and Engineering C, vol. 33, no. 3, pp. 13951402, 2013.

[11] C. S. Ciobanu, F. Massuyeau, L. V. Constantin, and D. Predoi, "Structural and physical properties of antibacterial Ag-doped nano-hydroxyapatite synthesized at $100^{\circ} \mathrm{C}$," Nanoscale Research Letters, vol. 6, article 613, 2011.

[12] X. Li, S. Li, M. Zhang, W. Zhang, and C. Li, "Evaluations of antibacterial activity and cytotoxicity on Ag nanoparticles," Rare Metal Materials and Engineering, vol. 40, no. 2, pp. 209214, 2011.

[13] C. S. Ciobanu, S. L. Iconaru, P. le Coustumer, L. V. Constantin, and D. Predoi, "Antibacterial activity of silver-doped hydroxyapatite nanoparticles against gram-positive and gram-negative bacteria," Nanoscale Research Letters, vol. 7, article 324, 2012.

[14] C. S. Ciobanu, S. L. Iconaru, M. C. Chifiriuc, A. Costescu, P. Le Coustumer, and D. Predoi, "Synthesis and antimicrobial activity of silver-doped hydroxyapatite nanoparticles," BioMed Research International, vol. 2013, Article ID 916218, 10 pages, 2013.

[15] A. Dudek and L. Adamczyk, "Properties of hydroxyapatite layers used for implant coatings," Optica Applicata, vol. 43, no. 1, pp. 143-151, 2013.

[16] D.-H. Kim, Y.-M. Kong, S.-H. Lee et al., "Composition and crystallization of hydroxyapatite coating layer formed by electron beam deposition," Journal of the American Ceramic Society, vol. 86, no. 1, pp. 186-188, 2003.

[17] K. Mediaswanti, C. Wen, E. P. Ivanova, C. C. Berndt, and J. Wang, "Sputtered hydroxyapatite nanocoatings on novel titanium alloys for biomedical applications," in Titanium AlloysAdvances in Properties Control, J. Sieniawski and W. Ziaja, Eds., pp. 21-44, InTech, Rijeka, Croatia, 2013.

[18] J. C. Selby, M. A. Shannon, and J. Biochem, "A method to fabricate mesoscopic freestanding polydimethylsiloxane membranes used to probe the rheology of an epithelial sheet," Journal of Biochemical and Biophysical Methods, vol. 70, no. 6, pp. 932944, 2008.

[19] P. Ingram, M. Im, S. McDermott, M. Wicha, and E. Yoon, "Spheroid cell culture on PDMS hydrophobic surfaces and integration into microfludic devices," in Proceedings of the International Conference on Miniaturized Systems for Chemistry and Life Sciences (MicroTAS '11), J. Landers, Ed., pp. 1539-1541, Seattle, Wash, USA, 2011.

[20] S. L. Iconaru, P. Chapon, P. le Coustumer, and D. Predoi, "Antimicrobial activity of thin solid films of silver doped hydroxyapatite prepared by sol-gel method," The Scientific World Journal, vol. 2014, Article ID 165351, 8 pages, 2014.

[21] A. Costescu, I. Pasuk, F. Ungureanu et al., "Physico-chemical properties of nano-sized hexagonal hydroxyapatite powder synthesized by sol-gel," Digest Journal of Nanomaterials and Biostructures, vol. 5, no. 4, pp. 989-1000, 2010.

[22] A. Aminian, M. Solati-Hashjin, A. Samadikuchaksaraei et al., "Synthesis of silicon-substituted hydroxyapatite by a hydrothermal method with two different phosphorous sources," Ceramics International, vol. 37, no. 4, pp. 1219-1229, 2011.

[23] K. A. Hing, P. A. Revell, N. Smith, and T. Buckland, "Effect of silicon level on rate, quality and progression of bone healing within silicate-substituted porous hydroxyapatite scaffolds," Biomaterials, vol. 27, no. 29, pp. 5014-5026, 2006.

[24] A. Balamurugan, A. H. S. Rebelo, A. F. Lemos, J. H. G. Rocha, J. M. G. Ventura, and J. M. F. Ferreira, "Suitability evaluation of sol-gel derived Si-substituted hydroxyapatite for dental and maxillofacial applications through in vitro osteoblasts response," Dental Materials, vol. 24, no. 10, pp. 1374-1380, 2008.

[25] N. Hijon, M. V. Cabanas, J. Pena, and M. Vallet-Regi, "Dip coated silicon-substituted hydroxyapatite films," Acta Biomaterialia, vol. 2, no. 5, pp. 567-574, 2006.

[26] C. M. Botelho, M. A. Lopes, I. R. Gibson, S. M. Best, and J. D. Santos, "Structural analysis of Si-substituted hydroxyapatite: zeta potential and X-ray photoelectron spectroscopy," Journal of Materials Science: Materials in Medicine, vol. 13, no. 12, pp. 1123-1127, 2002.

[27] T. Liu, D. Lai, X. Feng, H. Zhu, and J. Chen, "Synthesis and characterization of a novel mesoporous bioactive glass/hydroxyapatite nanocomposite," Materials Letters, vol. 92, pp. 444-447, 2013.

[28] A. Hilonga, J. K. Kim, P. B. Sarawade, and H. T. Kim, "Influence of annealing conditions on the properties of reinforced silverembedded silica matrix from the cheap silica source," Applied Surface Science, vol. 256, no. 9, pp. 2849-2855, 2010.

[29] S. Zhang, F. Xu, Y. Wang, W. Zhang, X. Peng, and F. Pepe, "Silica modified calcium alginate-xanthan gum hybrid bead composites for the removal and recovery of $\mathrm{Pb}$ (II) from aqueous solution," Chemical Engineering Journal, vol. 234, pp. 33-42, 2013.

[30] S. L. Iconaru, M. Motelica-Heino, and D. Predoi, "Study on europium-doped hydroxyapatite nanoparticles by fourier transform infrared spectroscopy and their antimicrobial properties," Journal of Spectroscopy, vol. 2013, Article ID 284285, 10 pages, 2013.

[31] Y. Leung and M. A. Walters, "Second derivative infrared spectra of hydroxyapatite," Spectrochimica Acta, vol. 46, pp. 1453-1459, 1990.

[32] M. Markovik, B. O. Fowler, and M. S. Tung, "Preparation and comprehensive characterization of a calcium hydroxyapatite reference material," Journal of research of the National Institute of Standards and Technology, vol. 109, p. 553, 2004.

[33] Y. Wang, X. Zhang, J. Yan, Y. Xiao, and M. Lang, "Surface modification of hydroxyapatite with poly(methyl methacrylate) via surface-initiated ATRP," Applied Surface Science, vol. 257, pp. 6233-6238, 2011.

[34] S. Agathopoulos, D. U. Tulyaganov, J. M. G. Ventura, S. Kannan, M. A. Karakassides, and J. M. F. Ferreira, "Formation of 
hydroxyapatite onto glasses of the $\mathrm{CaO}-\mathrm{MgO}-\mathrm{SiO}_{2}$ system with $\mathrm{B}_{2} \mathrm{O}_{3}, \mathrm{Na}_{2} \mathrm{O}, \mathrm{CaF}_{2}$ and $\mathrm{P}_{2} \mathrm{O}_{5}$ additives," Biomaterials, vol. 27, no. 9, pp. 1832-1840, 2006.

[35] L. M. Miller, V. Vairavamurthy, M. R. Chance et al., "In situ analysis of mineral content and crystallinity in bone using infrared micro-spectroscopy of the $\mathrm{v}_{4} \mathrm{PO}_{4}{ }^{3-}$ vibration," Biochimica et Biophysica Acta, vol. 1527, no. 1-2, pp. 11-19, 2001.

[36] G. Socrates, Infrared Characteristic Group Frequencies, John Wiley \& Sons, Chichester, UK, 2nd edition, 1994.

[37] B. J. Saikia, G. Parthasarathy, and N. C. Sarmah, "Fourier transform infrared spectroscopic estimation of crystallinity in $\mathrm{SiO}_{2}$ based rocks," Bulletin of Materials Science, vol. 31, no. 5, pp. 775-779, 2008.

[38] J. Jovanovic, B. Adnadjevic, M. Kicanovic, and D. Uskokovic, "The influence of hydroxyapatite modification on the crosslinking of polydimethylsiloxane/HAp composites," Colloids and Surfaces B: Biointerfaces, vol. 39, no. 4, pp. 181-186, 2004.

[39] L. Armelao, R. Bertoncello, and M. De Dominicis, "Silver nanocluster formation in silica coatings by the sol-gel route," Advanced Materials, vol. 9, no. 9, pp. 736-741, 1997.

[40] G. P. Shevchenko, S. V. Vashchanka, Y. V. Bokshits, and S. K. Rakhmanov, "On the nature of the processes occurring in silver doped $\mathrm{SiO}_{2}$ films under heat treatment," Journal of SolGel Science and Technology, vol. 45, no. 2, pp. 143-149, 2008.

[41] S. Hayakawa, T. Kanaya, K. Tsuru et al., "Heterogeneous structure and in vitro degradation behavior of wet-chemically derived nanocrystalline silicon-containing hydroxyapatite particles," Acta Biomaterialia, vol. 9, no. 1, pp. 4856-4867, 2013.

[42] C. S. Ciobanu, E. Andronescu, B. S. Vasile, C. M. Valsangiacom, R. V. Ghita, and D. Predoi, "Looking for new synthesis of hydroxyapatite doped with europium," Optoelectronics and Advanced Materials, Rapid Communications, vol. 4, no. 10, pp. 1515-1519, 2010.

[43] A. V. Lluch, G. G. Ferrer, and M. M. Pradas, "Biomimetic apatite coating on $\mathrm{P}\left(\mathrm{EMA}-\mathrm{co}\right.$-HEA)/ $\mathrm{SiO}_{2}$ hybrid nanocomposites," Polymer, vol. 50, no. 13, pp. 2874-2884, 2009.

[44] L. J. Bellamy, The Infrared Spectra of Complex Molecules, John Wiley \& Sons, New York, NY, USA, 3rd edition, 1975.

[45] L. Duta, F. N. Oktar, G. E. Stan et al., "Novel doped hydroxyapatite thin films obtained by pulsed laser deposition," Applied Surface Science, vol. 265, pp. 41-49, 2013.

[46] L. G. Benning, V. R. Phoenix, N. Yee, and M. J. Tobin, "Molecular characterization of cyanobacterial silicification using synchrotron infrared micro-spectroscopy," Geochimica et Cosmochimica Acta, vol. 68, no. 4, pp. 729-741, 2004.

[47] C. S. Ciobanu, F. Massuyeau, E. Andronescu, M. S. Stan, A. Dinischiotu, and D. Predoi, "Biocompatibility study of europium doped crystalline hydroxyapatite bioceramics," Digest Journal of Nanomaterials and Biostructures, vol. 6, no. 4, pp. 1639-1647, 2011.

[48] J. Kolmas, A. Jaklewicz, A. Zima et al., "Incorporation of carbonate and magnesium ions into synthetic hydroxyapatite: the effect on physicochemical properties," Journal of Molecular Structure, vol. 987, no. 1-3, pp. 40-50, 2011.

[49] B. Matsuhiro and P. Rivas, "Second-derivative Fourier transform infrared spectra of seaweed galactans," Journal of Applied Phycology, vol. 5, no. 1, pp. 45-51, 1993.

[50] E. Gómez-Ordóñez and P. Rupérez, "FTIR-ATR spectroscopy as a tool for polysaccharide identification in edible brown and red seaweeds," Food Hydrocolloids, vol. 25, no. 6, pp. 1514-1520, 2011.
[51] C. L. Popa, C. S. Ciobanu, S. L. Iconaru et al., "Systematic investigation and in vitro biocompatibility studies on mesoporous europium doped hydroxyapatite," Central European Journal of Chemistry, vol. 12, no. 10, pp. 1032-1046, 2014.

[52] R. V. Ghita, S. L. Iconaru, C. L. Popa et al., "Tetraethyl orthosilicate coated hydroxyapatite powders for lead ions removal from aqueous solutions," Journal of Nanomaterials, vol. 2014, Article ID 176426, 7 pages, 2014.

[53] A. Groza, A. Surmeian, M. Ganciu, and I. I. Popescu, "Infrared spectral investigation of organosilicon compounds under corona charge injection in air at atmospheric pressure," Journal of Optoelectronics and Advanced Materials, vol. 7, no. 5, pp. 2545-2548, 2005.

[54] M. Goldman and A. Goldman, "Corona discharges," in Gaseous Electronics, M. N. Hirsh and H. J. Oskam, Eds., vol. 1, pp. 219290, Academic Press, New York, NY, USA, 1978.

[55] K.-S. Koh, J. Chin, J. Chia, and C.-L. Chiang, "Quantitative studies on PDMS-PDMS interface bonding with piranha solution and its swelling effect," Micromachines, vol. 3, no. 2, pp. 427-441, 2012.

[56] B.-D. Hahn, J.-M. Lee, D.-S. Park et al., "Aerosol deposition of silicon-substituted hydroxyapatite coatings for biomedical applications," Thin Solid Films, vol. 518, no. 8, pp. 2194-2199, 2010.

[57] D. Marchat, M. Zymelka, C. Coelho et al., "Accurate characterization of pure silicon-substituted hydroxyapatite powders synthesized by a new precipitation route," Acta Biomaterialia, vol. 9, no. 6, pp. 6992-7004, 2013.

[58] H. Aguiar, J. Serra, P. González, and B. León, “Structural study of sol-gel silicate glasses by IR and Raman spectroscopies," Journal of Non-Crystalline Solids, vol. 355, no. 8, pp. 475-480, 2009.

[59] K. Shimizu, H. Habazaki, P. Skeldon, and G. E. Thompson, "Radiofrequency GDOES: a powerful technique for depth profiling analysis of thin films," Surface and Interface Analysis, vol. 35, no. 7, pp. 564-574, 2003. 

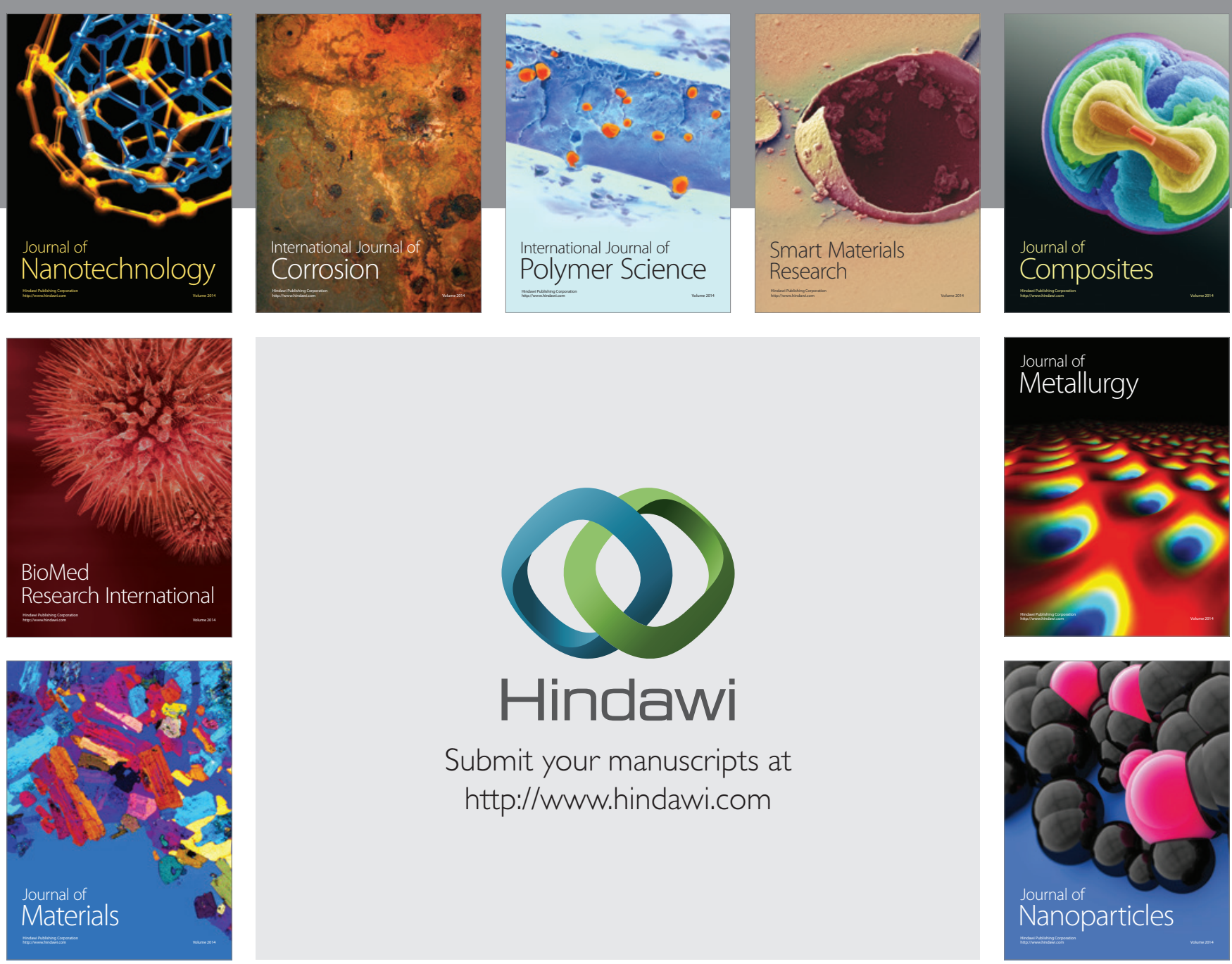

Submit your manuscripts at http://www.hindawi.com
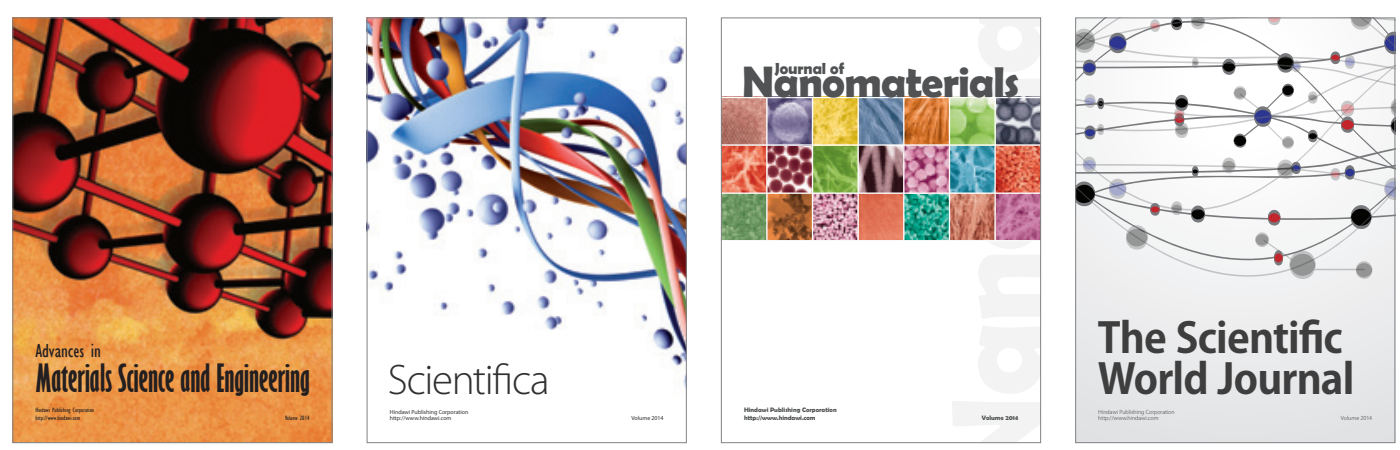

\section{The Scientific World Journal}
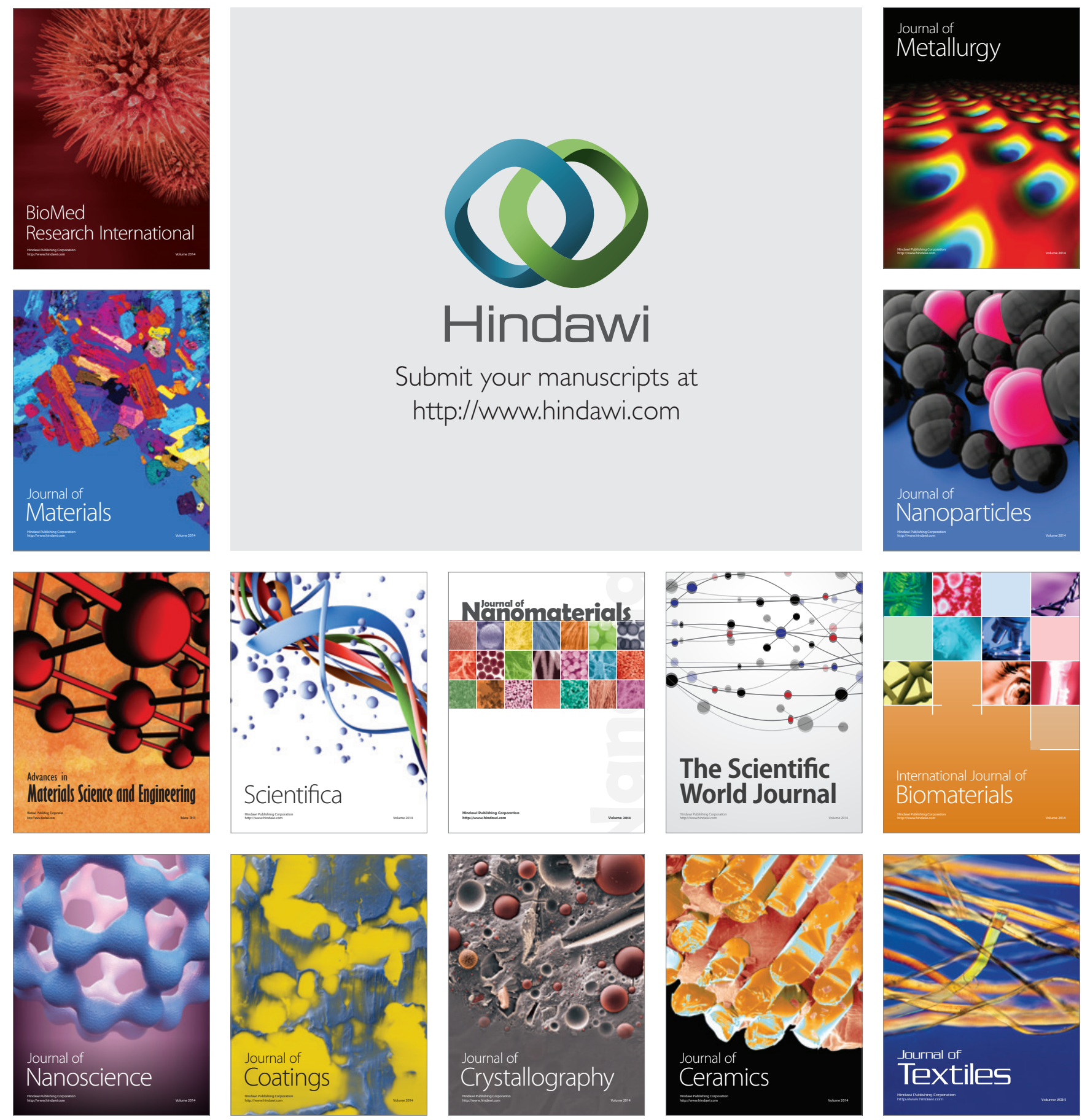